\title{
El trofeo y los rituales de victoria como símbolos del poder en el mundo helenístico*.
}

\author{
María del Mar Gabaldón Martínez \\ Instituto de Humanidades Ángel Ayala, Universidad San Pablo CEU.
}

A Pedro Pablo

in memoriam

\section{Resumen}

En el mundo griego el lenguaje vinculado a la victoria militar se transformó en el siglo IV a. C. En la Grecia arcaica y clásica la victoria solía ser presentada mayoritariamente como algo transitorio e impersonal, ligado sobre todo a la figura del ciudadano guerrero y de la polis en general. En cambio, en el mundo helenístico su conmemoración se convirtió en algo más duradero, normalmente personalizado en la figura del dirigente vencedor, y en un importante instrumento de propaganda.

La difusión entre la población de la victorias militares y su transformación en expresión de poder era llevada a cabo a través de una serie de mecanismos que incluían la construcción de monumentos conmemorativos, la celebración de rituales (consagración de las armas y de otras ofrendas en los santuarios, las procesiones triunfales, sacrificios a los dioses, etc.) y, por último, la creación de una ideología vinculada a la victoria a través de canales de propaganda como la literatura o las acuñaciones de monedas con la imagen del vencedor.

Palabras clave: Mundo helenístico, victoria, trofeos, monumentos conmemorativos, procesiones triunfales.

\begin{abstract}
There was a change along the Fourth Century B.C. in the way the vocabulary linked to military victory was used in the Greek world. In Archaic and Classical Greece victory was commonly presented as something transitory and not related to any individual. In fact, military victory was considered to be something about the polis and the citizen-warrior taken as general principles. However, in the Hellenistic world the commemoration of victories developed into something more permanent being identified with the figure of the triumphant ruler and so becoming a key political propaganda instrument.

The diffusion of this propaganda about military victories and its transformation into an image of power was performed through a number of mechanisms that included the building of commemoration monuments, the celebration of rituals (consecration of arms and other offerings, sacrifices to gods...) and the development of an ideology of victory in literature and coinage.
\end{abstract}

Keywords: Hellenistic world, victory, trophies, commemoration monuments, triumphal processions.

Dejar testimonio y memoria de la victoria, como instrumento de propaganda y de poder, tras la batalla ganada ha sido una constante en la historia de la guerra.
En uno de sus trabajos más recientes, el profesor Tonio Hölscher ${ }^{1}$ ha señalado que las victorias militares son por lo general acontecimientos de corta duración, y para que estas hazañas en el

\footnotetext{
* Trabajo realizado en el marco del Proyecto BHA 2001-0187 " La imagen de las armas en la Iberia prerromana".
}

1 Hölscher, T. (2003): "Images of war in Greece and Rome: between military practicee, public memory, and cultural symbolism ”, Journal of Roman Studies, 92, 1-17. 
campo de batalla lleguen a ser expresión de poder tienen que ampliar su marco espacial y temporal, siendo difundidas a través de la creación de monumentos que las conmemoran, de la celebración de ceremonias públicas y de la creación de una ideología unida a la victoria.

Este lenguaje vinculado al éxito militar se transformó con el comienzo el período helenístico (quizá algo antes). Ya que mientras en la Grecia clásica, y sobre todo en la arcaica, la victoria solía ser presentada mayoritariamente como algo transitorio e impersonal, ligado sobre todo a la figura del guerrero y de la polis en general, en el mundo helenístico su conmemoración se convirtió en algo más duradero, normalmente personalizado en la figura del dirigente vencedor, y en un claro instrumento de propaganda.

Esta transformación iba de la mano del nuevo orden político, pero también estaba relacionada con los cambios producidos en el modo de entender y hacer la guerra que se estaban llevando a cabo desde el siglo IV a. C.

Como escribió hace algunos años J. J. Pollit (1998, 49), en época helenística el culto al gobernante sirvió como base y justificación de gran parte del nuevo orden político del período, y se hizo claramente imperativo persuadir a los súbditos de los distintos reyes para que aceptaran y respetaran la institución. De este modo las artes visuales, en las que se incluyen los monumentos erigidos para conmemorar las victorias militares, se convirtieron en el medio idóneo para ganar esa aceptación y respeto y para dar a conocer la política y los logros del gobernante.

Ahora bien, esto no quiere decir que en las épocas precedentes la presentación de la victoria

2 Sobre la Estoa Pintada (Stoa Poikile) vid. Pausanias I, 15, $1-4$

Tras la Batalla de Maratón se construyeron varios monumentos que evocaban la victoria en los que aparecían los vencedores junto a los dioses y héroes legendarios, como es el caso de la basa de un monumento dedicado en Delfos que contenía estatuas de Apolo, Atenea y once héroes (los llamados héroes epónimos) junto a Milcíades (Pausanias, X, 10, 1).

3 Sobre el trofeo de mármol blanco de Maratón vid. Pausanias I, 32, 5; también es mencionado por Aristófanes en Los Caballeros, 1334 y por Platón en Menexenus, 240D y 245A.

Los restos del monumento fueron hallados en Maratón en la década de los sesenta del siglo pasado (Vanderpool, 1966). Se trataría de una columna jónica coronada por una estatua, quizá una Niké o un tropaion.

4 Sobre la dedicación de armas en los santuarios griegos no fuera utilizada para transmitir mensajes políticos. Basta con recordar los numerosos monumentos que conmemoraban victorias militares en los santuarios o el recuerdo duradero que quisieron dejar los atenienses tras derrotar a los persas, algo que podía verse en algunas de las escenas de la Estoa Pintada del ágora de Atenas ${ }^{2}$ o en el trofeo de mármol blanco construido en la llanura de Maratón ${ }^{3}$. Asimismo, las numerosas armas procedentes del botín, que sobre todo, en época tardoarcaica, adornaban los pórticos y muros de los templos de muchos santuarios griegos $^{4}$, no sólo eran manifestaciones de piedad religiosa, también contenían un mensaje político, que destacaba el poder de la polis vencedora ${ }^{5}$.

Sin embargo, aunque en algunos monumentos de victoria de época clásica se podían incluir retratos de generales o sus nombres como es el caso del monumento dedicado en Delfos por los espartanos para conmemorar su victoria frente a los atenienses en Egospótamos en el 405 a. C., en el que figuraban las estatuas de Lisandro y de muchos de los participantes en aquella batalla, normalmente se trataba de monumentos impersonales que daban relieve a los acontecimientos y a las ciudades implicadas en ellos, pero que apenas resaltaban personalidades concretas. Así, en las inscripciones que llevaban algunas de las armas halladas en los santuarios solía especificarse el nombre de la población vencedora y de la vencida u otras circunstancias relacionadas con su captura, y en contadas ocasiones se indicaba el nombre de una persona concreta. Dos excepciones son por ejemplo, los cascos ofrecidos por Hierón de Siracusa tras la victoria de Cumas sobre los etruscos $(474 \text { a. C. })^{7}$ o el ejemplar corintio que al parecer fue dedicado al dios de

y en otros ámbitos del Mediterráneo vid. Gabaldón Martínez, M. M. (2003): Ritos de armas en la Edad del Hierro. Lugares de culto y armamento en el ámbito circunmediterráneo. Tesis Doctoral defendida en la Universidad Autónoma de Madrid.

5 Para exhibir las glorias militares, las armas no sólo eran colocadas en los edificios sagrados, también se mostraban en los pórticos de las ágoras de las ciudades, como en la Estoa Pintada o el Pórtico de Zeus Eleutereo en Atenas o en el Pórtico Oeste del santuario de Delfos donde se colocaron las armas que los etolios tomaron de los gálatas (Amandry, 1978).

6 Pausanias (X, 9, 7-10) describe este monumento enumerando los nombres de todos aquellos que figuran en el mismo, los cuales participaron con Lisandro en Egospótamos.

Sobre esta cuestión véase Rice, 1993, 226-227.

7 Sobre los cascos dedicados en Olimpia por Hierón de Siracusa vid. Meiggs y Lewis, 1988, 62, 29 (22). 


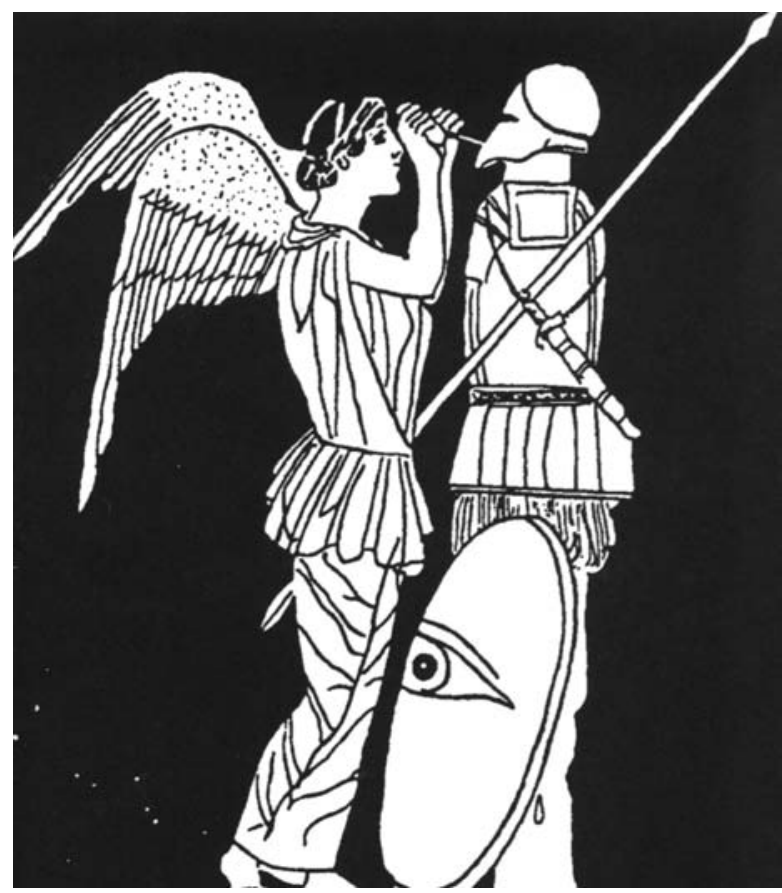

Fig. 1. Detalle de la pélice del Museo de Boston ("Pintor del Trofeo", siglo V a. C.), en el que una Niké construye el tropaion. Fuente: Janssen, 1957.

Olimpia por Milcíades, posiblemente después de Maratón, o quizá antes".

$\mathrm{Y}$ es que las celebraciones de victoria de las épocas arcaica y clásica enfatizaban, más que la propia victoria militar, el triunfo de la polis y el valor de sus ciudadanos como guerreros, mientras que las conmemoraciones helenísticas otorgaban la gloria al gobernante, como jefe victorioso, el cual aparecía dentro de una iconografía belicista como un guerrero en acción, en primera línea de combate .

En el período helenístico la difusión entre la población de la victorias militares era llevada a cabo mediante la construcción de monumentos conmemorativos, la celebración de rituales

8 Este yelmo corintio es una ofrenda individual de Milcíades, hecha probablemente antes de la batalla de Maratón, cuando el estratego ateniense era tirano de Quersoneso (Jacquemin, 1999, 144, n. 20).

9 Comenzando con la figura de Alejandro, que aparece en las escenas de batalla en primera línea de combate (mosaico de la "batalla de Iso").

10 Como las ofrendas de barcos o de proas, que tienen su trasunto en algunos monumentos conmemorativos de piedra que representan barcos (Rice, 1993, 242-247).

11 De hecho, la llanura de Maratón donde tuvo lugar la conocida batalla frente a los persas y en la que se construyeron un monumento conmemorativo (un trofeo de colectivos, que incluyen la consagración de las armas y de otras ofrendas en los santuarios, las procesiones triunfales y los sacrificios a los dioses, y, por último, la creación de una ideología vinculada a la victoria a través de canales de propaganda como la literatura o las acuñaciones monetales con la imagen del vencedor.

La construcción de monumentos conmemorativos y la ofrenda de armas en los lugares de culto serán los aspectos que se trataran en este trabajo con más detalle.

Los monumentos eran obras arquitectónicas o escultóricas conmemorativas, que podían ser erigidos en lugares de especial significado, ya fuera en o junto al campo de batalla, donde se levantaban los trofeos o tumbas colectivas en honor a los caídos; en los espacios fronterizos, y sobre todo en los santuarios y en el centro político, en la ciudad, donde la victoria tendría más eco y podía llegar a un mayor número de población.

El sentido etimológico de la palabra "monumento" deriva del verbo latino monere, hacer saber, recordar. Y esto es lo que se pretendía con los monumentos de victoria: proclamarla $\mathrm{y}$ recordarla; que se convirtiese en un acontecimiento duradero, y cuya sola visión legitimara, solidificara y extendiera el poder de los dirigentes.

Levantar monumentos conmemorativos en el lugar donde se había desarrollado la contienda aportaba no sólo una evocación de la victoria, sino también de la batalla, convirtiendo el lugar donde se había desarrollado el enfrentamiento en una suerte de espacio sagrado ${ }^{11}$.

Para los griegos de época clásica el levantar el trofeo en el campo de batalla suponía no sólo un símbolo tangible de la victoria, sino también un rito religioso bien establecido vinculado con la guerra agonal hoplita ${ }^{12}$.

mármol) y un túmulo (soros), donde fueron enterrados los ciento noventa y dos atenienses caídos en el enfrentamiento, se convirtió en una especie de lugar sagrado al que acudían los habitantes de Maratón varias centurias después de la batalla. En tiempos de Pausanias (I, 32, 3-4) todavía pervivían estos monumentos y el culto heroico junto a la tumba.

12 La bibliografía sobre el trofeo griego es muy extensa; vid. una revisión de la misma en Gabaldón, 1997; Gabaldón, 1999. En último lugar está el trabajo de M. Betalli (e. p.), y para su vinculación con la guerra agonal hoplita véase el sugerente trabajo de Peter Krentz (2002). 
En la antigua Grecia existían dos tipos de trofeo. El trofeo de armas, el tronco de árbol con ropaje y armamento, que le dan un apariencia humana (fig. 1), y que es sin duda el tropaion griego por excelencia, cuyo origen debe remontarse al menos a la primera mitad del siglo $\mathrm{V}$ a. C., y el trofeo, que puede denominarse "permanente", construido en piedra o bronce, que suele estar decorado con representaciones de armas enemigas, victorias o trofeos. Los restos más antiguos de este tipo de tropaia pertenecen a las construcciones conmemorativas que se erigieron durante las Guerras Persas, como el ya mencionado trofeo de mármol de Maratón ${ }^{13}$.

Las diferencias entre ambos tipos de trofeos construidos en el campo de batalla nos dan una clave para entender las diferencias en la forma de conmemorar la victoria en época clásica y en el periodo helenístico.

El trofeo construido con armas era básicamente una dedicación a uno o varios dioses, especialmente a Zeus Tropaios ${ }^{14}$ a quien se le atribuía la victoria; estaba protegido por una sanción divina y se respetaba, incluso siendo construido en territorio enemigo. Desde el punto de vista jurídico la costumbre del trofeo era el límite, tanto geográfico como simbólico, que los vencedores imponían a los vencidos prohibiéndoles ir más allá de él bajo pena de incurrir en el pecado de hybris (Fernández Nieto, 1975, 111) ${ }^{15}$. Además, no podía haber victoria sin trofeo, ni trofeo sin victoria. En ocasiones, cuando el hecho de la victoria no era claro, o ambos contendientes la reclamaban se podían levantar dos tropaia, como en Mantinea, donde tanto tebanos como lacedemonios, levantaron un trofeo por cada lado porque ambos se consideraban vencedores ${ }^{16}$.

El tropaion de la guerra de hoplitas no era un monumento conmemorativo; era la marca de la victoria, aunque de forma transitoria, ya que al estar construido en un armazón de madera, con armas y ropajes no podría durar eternamente, algo que no ocurriría con los trofeos pétreos cuyo fin era perpetuar la evocación de la victoria y con ello el de la batalla y el de los vencedores. Esto

13 Vid. Pausanias I, 32, 5 (Maratón); I, 36, 1 (Salamina); IX, 2, 6 (Platea). Sobre los trofeos de las Guerras Persas vid. Wallace, 1969; West, 1969.

$14 \mathrm{El}$ nombre de Zeus Tropaios aparece, quizá por primera vez, en las inscripciones de Maratón y Salamina (IG II2 1028, 1006), lo cual puede indicar que el culto de Zeus Tropaios pudo comenzar en el Ática tras las Guerras Persas.

15 En el apartado VIII de su libro, Z. Gansiniec hace una

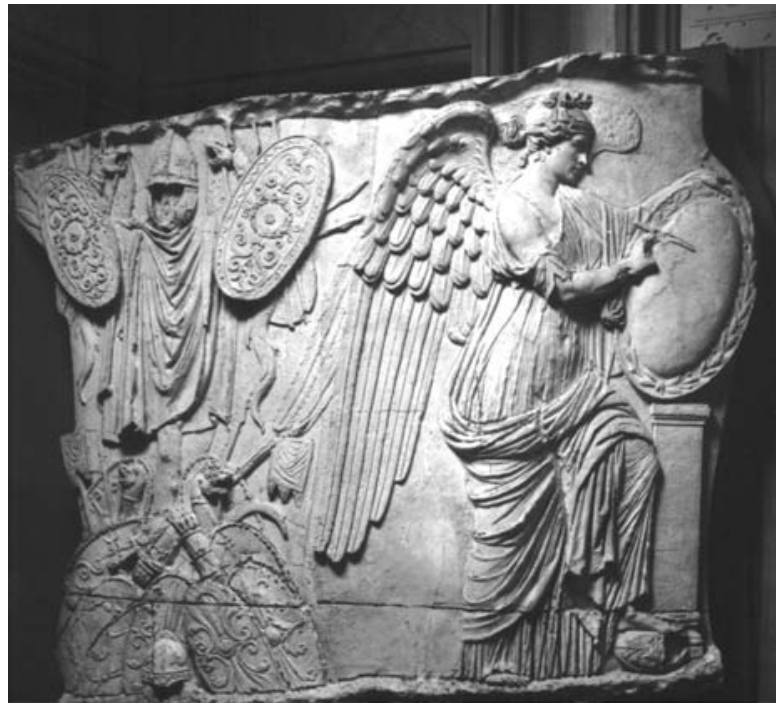

Fig. 2. Victoria inscribiendo sobre un clipeus junto a un trofeo de armas de la Columna Trajana. Copia del Museo de la Civilización Romana. Foto: DAI Roma, neg. 31.356.

puede explicar que el primer monumento de este tipo fuera probablemente el de Maratón. Aquella batalla supuso la primera gran victoria sobre los persas y puso de relieve el poder de Atenas. Sobre aquella llanura, los atenienses levantaron un trofeo formado por una columna jónica coronada por la estatua de una Niké o un tropaion, y un túmulo funerario donde fueron enterrados los caídos en el enfrentamiento. Aquellos monumentos se habían construido para que las generaciones sucesivas conservasen la memoria de aquella victoria. Su fin era perdurar.

Como ya se ha señalado, los trofeos construidos con armas eran una forma de dedicación; una panoplia enemiga, ofrecida a la divinidad, al igual que las armas procedentes de los despojos dedicadas en los santuarios. Con la construcción de monumentos permanentes el sentido del trofeo, como ofrenda, pasa a un segundo lugar, mientras que su significado, como monumento conmemorativo y expresión de poder, se coloca en un primer plano.

Es muy probable que el paso de un tipo de

revisión de las normas jurídicas relacionadas con el trofeo (su carácter sacro, su inmunidad, derechos de erección, protestas por su levantamiento, etc.).

16 En consecuencia, en la Hélade hubo aún mayor indecisión y confusión después de la batalla que antes (Jenofonte, Helénicas VII, 5, 26, trad. Guntiñas Tuñón). Sobre la batalla indecisa entre Mantinea y Tegea (423-422 a. C.) y el levantamiento de dos trofeos, vide también Tucídides, IV, 134, 1-2. 
guerra de corte agonístico (la imperante en época clásica), definida por una serie de formalidades y rituales, basada en batallas fijadas en espacio y tiempo, a otra más extensa, con más efectivos, aunque no exenta, por supuesto, de componentes religiosos y rituales, influyó sin duda en la concepción del tropaion. El trofeo construido con las armas del adversario tenía, como ya se ha señalado, un carácter no permanente, como así eran esas breves batallas de hoplitas entre poleis. El tropaion se construía tras terminar la contienda y todo volvía a la normalidad. Ambas comunidades podían volver a enfrentarse en una nueva batalla y un trofeo volvía a ser levantado. El trofeo no debía ser destruido dada su naturaleza sagrada pero con el tiempo acabaría cayéndose; por tanto, tenía un carácter transitorio como las victorias de las batallas de hoplitas. Sin embargo, un trofeo permanente, como los construidos tras las guerras persas, no sólo conmemoraba y otorgaba eternidad a una batalla decisiva, especialmente frente a pueblos no griegos, también se convirtió en una forma de simbolizar las victorias de los largos enfrentamientos, que excedían el concepto de polis, los cuales fueron característicos en el mundo griego a partir del siglo IV a. C. En este cambio el espíritu del agón hoplita fue siendo sustituido poco a poco por el hegemónico; y un monumento permanente levantado en un lugar destacado se convirtió así en una de las mejores formas de conmemorar una victoria "total", no transitoria.

Por supuesto, el trofeo en época helenística siguió siendo un destacado símbolo de victoria. Por ejemplo, en la segunda mitad del siglo III a. C. una ley ateniense premiaba con privilegios a aquellos que hubiesen levantado un trofeo (Janssen, 1957, 244: Betelli, e. p.). Lo que ocurrió es que cambió de forma y de sentido; se convirtió en un motivo más personalizado destinado a conmemorar el poder del gobernante, algo que heredará Roma. Ya no es tanto una forma de dedicación u ofrenda, es fundamentalmente un

17 Para el trofeo romano véase el trabajo clásico de Picard, 1957.

18 Vid. Plinio, N. H. VI, 152

19 Josefo, XIII, 250.

20 Contra la reconstrucción del monumento propuesta por M. M. Markle véase Polito, 1998, 81, 99, n.60.

21 Diodoro menciona los trofeos levantados por Filipo tras una batalla frente a los ilirios (XVI, 4, 7) y después de Queronea (XVI, 86, 6). Sobre los trofeos macedonios véase Betalli e. $\mathrm{p}$.

22 Los macedonios dicen que Carano, rey de Macedonia, venció monumento conmemorativo, lo cual, explica, por otro lado, que el trofeo, como tronco de árbol vestido con una panoplia se convierta más bien en un elemento iconográfico relacionado con la simbología de la victoria y el triunfo, siendo este motivo uno de los más característicos del arte triunfal helenístico e imperial, que aparece en no pocos soportes (fig. 2) ${ }^{17}$.

Las fuentes escritas mencionan algunos de los trofeos construidos por los reyes helenísticos, especialmente los seleúcidas, como los dos construidos por Numenio, general de Antíoco III ${ }^{18}$ tras una doble victoria, en tierra y mar, sobre los persas, o el erigido por Antíoco VII Sidetes tras derrotar a los partos, el cual es mencionado por Flavio Josefo ${ }^{19}$.

Otro ejemplo puede ser el monumento levantado en Veria, en Macedonia, decorado con escudos hoplitas y macedónicos, que fue construido para conmemorar la victoria de Pirro sobre Demetrio I Poliorcetes, y su proclamación como rey de Macedonia en el año 287 a. C. (Markle, 1994; Markle, $1999^{20}$ ).

Sin embargo, no parece que los primeros soberanos macedonios tuvieran por costumbre construir trofeos en el campo de batalla. Al parecer, Alejandro no erigió ningún trofeo de armas para celebrar sus victorias militares; y respecto a Filipo II sólo existen dos testimonios recogidos por Diodoro de Sicilia ${ }^{21}$.

Según una leyenda recogida por Pausanias (IX, 40, 7-9), un león llegado del Olimpo destruyó un trofeo erigido por Carano, el legendario fundador de la casa real macedonia ${ }^{22}$, por lo tanto construir un trofeo era considerado por los macedonios un especie de tabú (Diodoro, XVIII, 15). Resulta, por tanto, curioso que algunos monumentos con leones fueron asociados tanto en época clásica como helenística con la conmemoración de la victoria y de la guerra, especialmente como cenotafios o tumbas de los caídos. Ejemplos de estos monumentos, son el majestuo-

en batalla a Ciseo, que era jefe en una región vecina. Este Carano levantó un trofeo siguiendo las leyes de los argivos por su victoria, pero dicen que un león vino del Olimpo y derribando el trofeo éste desapareció (...). Con una reflexión: Carano no había tenido una buena política al llegar a una enemistad irreconciliable con los bárbaros que vivían alrededor, y se estableció que no debía levantar trofeos ni el propio Carano ni los que iban a reinar después en Macedonia, si es que algún día debían atraerse la amistad de sus vecinos. Lo que digo lo confirma también Alejandro, que no levantó trofeos ni por su victoria sobre Darío ni por sus victorias de la India. (Pausanias IX, 40, 8, trad. M. C. Herrero). 

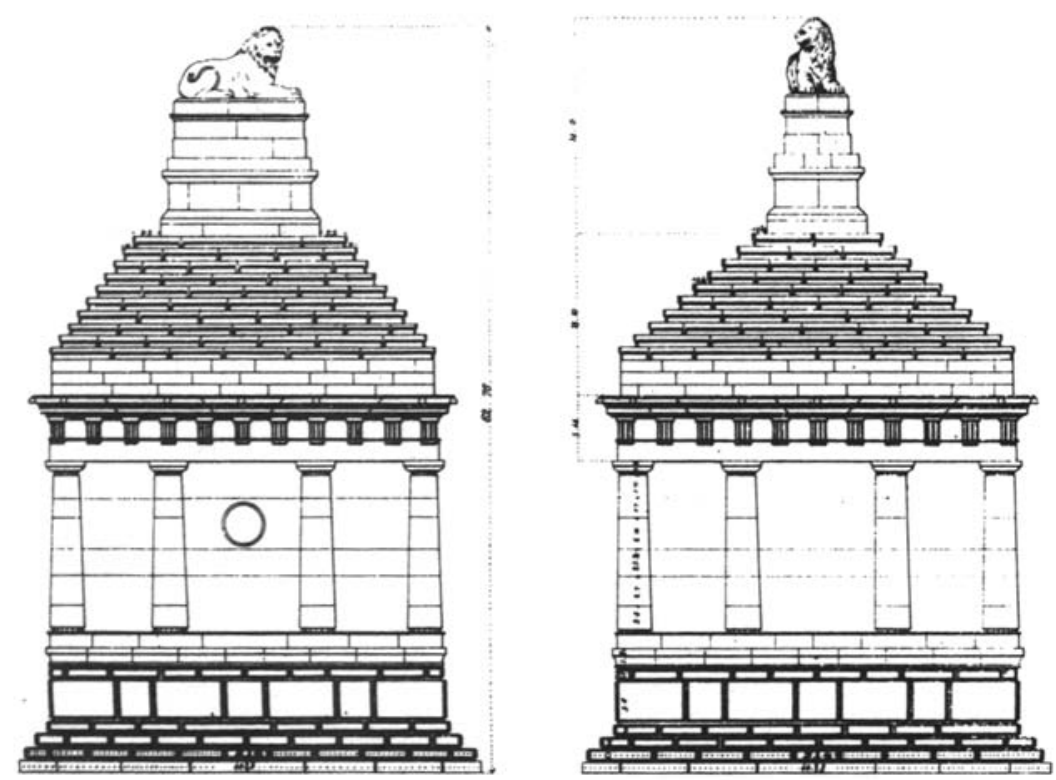

Fig. 3. Hipotética reconstrucción de la tumba de Cnido (según R. P. Pullan) coronada con un león, levantada en un promontorio probablemente para conmemorar una batalla naval. Fuente: Rice, 1993.

trofeos erigidos en el campo de batalla. Se levantaron para recordar una victoria, como expresión de poder y como hitos, en un emplazamiento que serviría para visualizar una delimitación provincial, lo cual les añadiría un destacado valor ideológico. Algo parecido ocurría con el gran trofeo de Augusto en los Alpes, levantado para celebrar la pacificación de todo el arco alpino, situado en un espacio dominante, punto de paso obligado de una importante vía de comunicación ${ }^{25}$.

Evidentemente estos monumentos destinados a celebrar la victoria en espacios geográficos con cierta carga simbólica, como podía ser el lugar del enfrentamiento bélico y los territorios fronterizos se convertían también en instrumentos políticos como hitos de un espacio controlado, pero también

so león de mármol de Queronea, que recuerda el lugar donde fueron enterrados los tebanos caídos frente a los macedonios de Filipo en el 338 a. C., el monumento funerario de Anfípolis coronado por un león ${ }^{23}$, o la tumba de Cnido (fig. 3), construida en un promontorio probablemente para conmemorar una batalla naval ocurrida en algún momento de finales del siglo IV o principios del siguiente (Rice, 1993, 249-251).

Desde luego, los monumentos construidos en el campo de batalla, ya fueran trofeos o tumbas, tenían un claro valor psicológico, como recuerdos duraderos de las batallas y sus victorias, pero también como señalizadores de lugares especiales, colocados en terrenos bien visibles. Al igual que los monumentos de victoria romanos construidos en zonas fronterizas o junto a importantes vías de comunicación, como los identificados en el Pirineo Oriental, construidos en un terreno limítrofe entre la Citerior y la Narbonense para conmemorar las victorias de Pompeyo sobre galos e hispanos. ${ }^{24}$ Se trata sin duda de monumentos conmemorativos, pero no son auténticos como manifestaciones de la extensión del poder.

Con todo, la escenificación de las victorias militares a través de los monumentos tendría seguramente una mayor audiencia en los lugares de culto, especialmente en los santuarios panhelénicos, como Olimpia o Delfos, y en las ciudades. Ambos espacios, tanto el lugar de culto como la ciudad, se convirtieron en escenarios privilegiados en los que el gobernante podía comunicar su poder, político, militar y económico, embelleciéndolos con monumentos, gracias a la capacidad de crear y de transformar que va de la mano del poder político, pero también gracias a las victorias obtenidas en el campo de batalla.

Desde luego, William Kendrik Pritchett (1971, 100) no exageraba cuando escribió que sin las guerras, pocos de los templos y monumentos de Grecia habrían sido construidos.

Dentro de estas obras que recordaban la victoria en los centros políticos y religiosos, hay que señalar en primer lugar el "Monumento del Gránico", probablemente la obra más destacada

25 De igual modo, el trofeo de Adamclisi, que conmemoraba la victoria del emperador Trajano sobre los dacios, fue también construido sobre cierta altura junto a un nudo viario. 
del arte triunfal de la Antigüedad ${ }^{26}$. Este grupo escultórico creado por Lisipo en Dión, el centro sagrado de los macedonios, en memoria de los que murieron en la primera gran victoria de Alejandro sobre los persas, estaba formada por varias estatuas de infantes y jinetes de bronce, entre las cuales había seguramente un retrato del propio Alejandro. Como muchas de las obras de Lisipo, el monumento ejerció una enorme influencia para el período helenístico. En palabras de Pollit (1998, 85), "su historicidad tocó la fibra del individualismo helenístico; su aparente realismo bélico conmovió la mentalidad teatral de la época; y la imagen triunfante de Alejandro evocaría la fortuna irresistible del rey y hablaría de así a la obsesión helenística por Tykhe”.

Seguramente se erigieron muchos otros monumentos de este tipo en las ciudades y santuarios del mundo griego. Pausanias describe varias dedicaciones en el santuario de Olimpia en recuerdo de hazañas militares relacionadas con Seleuco ${ }^{27}$, Demetrio Poliorcetes ${ }^{28}$ y Antígono ${ }^{29}$.

Pero, los más claros sucesores del tipo de monumento real conmemorativo iniciado por el de la batalla del río Gránico fueron sin duda los grandes grupos atálidas construidos en Pérgamo, que conmemoraban las victorias sobre los gálatas.

Todas estas obras de arte se convirtieron no sólo en símbolos de victoria, sino en claras manifestaciones del poder y carisma de los soberanos helenísticos, que enriquecían sus ciudades y espacios de culto gracias a sus logros militares.

Por lo tanto, no es de extrañar que muchos de estos monumentos y otras obras artísticas fueran objeto de los saqueos de los generales romanos victoriosos en suelo griego y fueran exhibidos con gran pompa como botín de guerra en los desfiles triunfales por las calles de Roma .

Así, tras la conquista final de Macedonia, Cecilio Metelo celebró en el año 146 a. C. su triunfo, trayendo consigo el monumento de vic-

26 Sobre el monumento y su composición vid. Arriano I, 16, 4; Plutarco, Alejandro XVI; Veleyo Patérculo, I, 11, 34. Vid. un estudio sobre el monumento en Calcani, 1989. Véase también Olaguer-Feliú, 2000, 102-103.

27 Pausanias VI, 11, 1.

28 Pausanias VI, 15, 7.

29 Pausanias VI, 16, 2.

30 Estos monumentos dejaron sin duda no sólo recuerdos duraderos de las victorias romanas en suelo heleno y un modo de enfatizar el poder del vencedor, sino también un medio de difusión de la cultura y el arte toria más importante del Helenismo, el conjunto escultórico de la batalla del Gránico de Lisipo, que fue colocado en el llamado Pórtico Metelo ${ }^{31}$, en el Campo de Marte, convirtiéndose de algún modo, y paradójicamente, en el monumento que conmemoraba la victoria definitiva de Metelo sobre los macedonios.

Años antes, en la procesión triunfal decretada en homenaje a Emilio Paulo en el año 167 a. C. desfilaron numerosos tesoros artísticos procedentes de Macedonia. Según relata Plutarco ${ }^{32}$, esta celebración duró tres días: el primer día fue apenas suficiente para ver las estatuas que se habian traido, y las pinturas y las imágenes colosales, todo ello llevado en 250 carros tirados por yuntas. En el segundo día pasaron en muchos carros las armas más hermosas y acabadas de los macedonios y las vasijas de plata.

Además de exhibir los despojos y su éxito militar sobre Macedonia en su desfile triunfal, a la manera romana, Emilio Paulo, siguiendo la estela de los gobernantes helenísticos, quiso dejar también en un santuario griego un recuerdo duradero de su victoria. De este modo, ordenó que se construyera en Delfos un monumento dedicado a la conmemoración de su propia persona y de la victoria romana de Pidna (168 a. C.) en la que derrotó al último rey de Macedonia ${ }^{33}$. Como señalan Plutarco ${ }^{34}$ y los datos arqueológicos, se trataba de un pedestal, que en origen debía estar coronado con una imagen del propio rey Perseo, y en el que finalmente se colocó la estatua ecuestre de Paulo. La parte superior estaba decorada con un friso con escenas de la batalla en la que los combatientes se pueden identificar por sus armamento como romanos y macedonios, y en la base de este pedestal podía leerse una inscripción: "L. Emilio, hijo de Lucio [lo erigió con los despojos que] tomó del rey Perseo y de los macedonios"

De este modo, Emilio Paulo aparecía en Roma como un vir triumphalis, un imperator, y en el santuario de Delfos, como un jefe victorioso,

griegos, algo que quedó magistralmente expresado en las palabras del poeta Horacio (Ep II, 1, 156): Graecia capta ferum victorem cepit et artis / intulit agresti Latio.

31 Para el Pórtico Metelo vid. Pietilä-Castrén, 1987, 130132.

32 Plutarco, Emilio Paulo XXXII-XXXIII.

33 Para el monumento de Emilio Paulo en Delfos vid. Plutarco, Emilio Paulo XXVIII; Polibio XXX, 10, 2; Livio XLV, 27, 7.

34 Emilio Paulo XXVIII. 


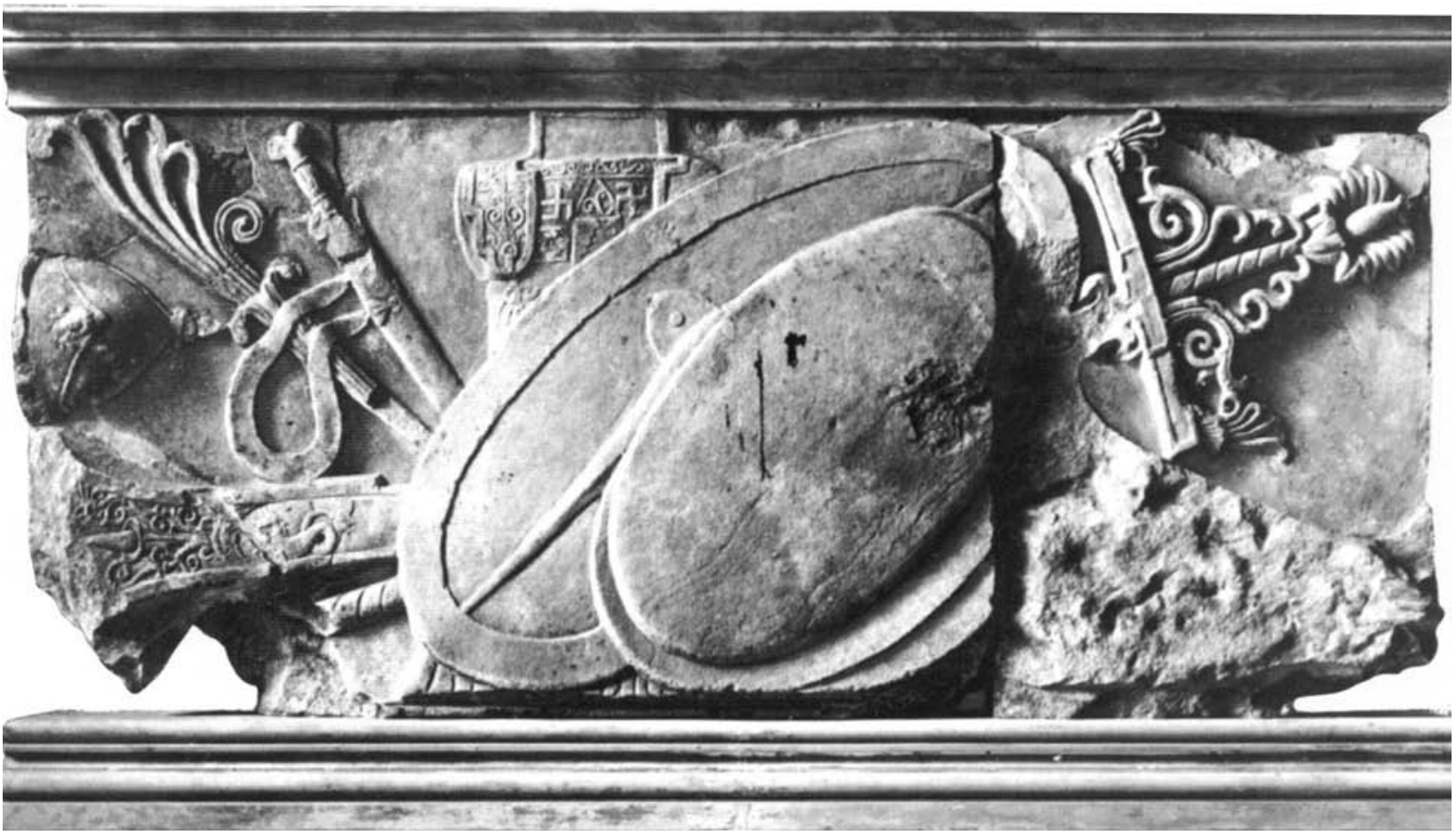

Fig. 4. Friso de armas amontonadas del recinto porticado del santuario de Atenea Polias de Pérgamo. Foto: Pergamonmusem, Berlín.

dejando el recuerdo petrificado de su victoria en un monumento personalizado, convirtiéndose en un héroe, al igual que lo habían hecho los soberanos helenísticos, empezando por Alejandro Magno.

Sin duda los imperatores romanos en su deseo de dejar recuerdos duraderos de sus victorias y de reafirmar y extender el poder de Roma, al tiempo que proclamar su carisma contaban con el ejemplo de los soberanos helenísticos y de los rituales griegos, ya fuera mediante la ofrenda de armas y monumentos en los lugares de culto o la construcción de trofeos en el campo de batalla.

Así, en Delos, al sur del pilar de Antíoco, una base de piedra representaba el amontonamiento de escudos macedónicos que un general romano había tomado en Grecia y dedicaba al dios Apolo $^{35}$. También el general romano Mumio ofreció en el santuario de Olimpia veintiún escudos dorados ${ }^{36}$, y el carismático Sila mandó erigir

\footnotetext{
35 Préaux, 1984, 17.

36 Pausanias V, 10, 5 .

37 Esta campaña fue descrita por Plutarco (Sila XIX, 910), y el viajero Pausanias (IX, 40, 7) menciona los dos trofeos "permanentes" que los romanos levantaron en aquel lugar. Es posible que uno de estos trofeos haya sido identificado recientemente (Camp et alii, 1992), lo
}

un trofeo, al modo helenístico, en las cercanías de Queronea para conmemorar su victoria sobre el ejército de Mitríades en el año 86 a. C. ${ }^{37}$ (Camp et alii, 1992).

Sin duda otra forma de celebrar la victoria y convertirla en expresión de poder consistía en honrar a los dioses y agradecer su ayuda haciéndoles partícipes del botín, llenando sus santuarios de ofrendas.

$\mathrm{Y}$ es que si la guerra victoriosa era condición de poder y de prestigio, también era proveedora del botín (con su valor económico, simbólico y religioso). Como ya se ha visto, el vencedor llevaba a las divinidades las primicias de su botín, materializadas en monumentos conmemorati$\operatorname{vos}^{38}$, y en la dedicación de las armas y otros objetos en los lugares de culto, especialmente en los grandes santuarios panhelénicos. Esta práctica fue muy frecuente en los periodos arcaico y clásico, aunque no tanto en época helenística.

cual ha sido puesto en duda por C. S. Mackay (2000, 168-177).

38 Como señala C. Préaux (1984, 17): "había un botín de carácter particular: las estatuas sagradas, robadas mucho tiempo antes por algún enemigo y que se iban a recuperar. Era el objetivo de la expedición de Alejandro, y fue también el de Ptolomeo Evergetes I en su campaña contra el Seleúcida”. 


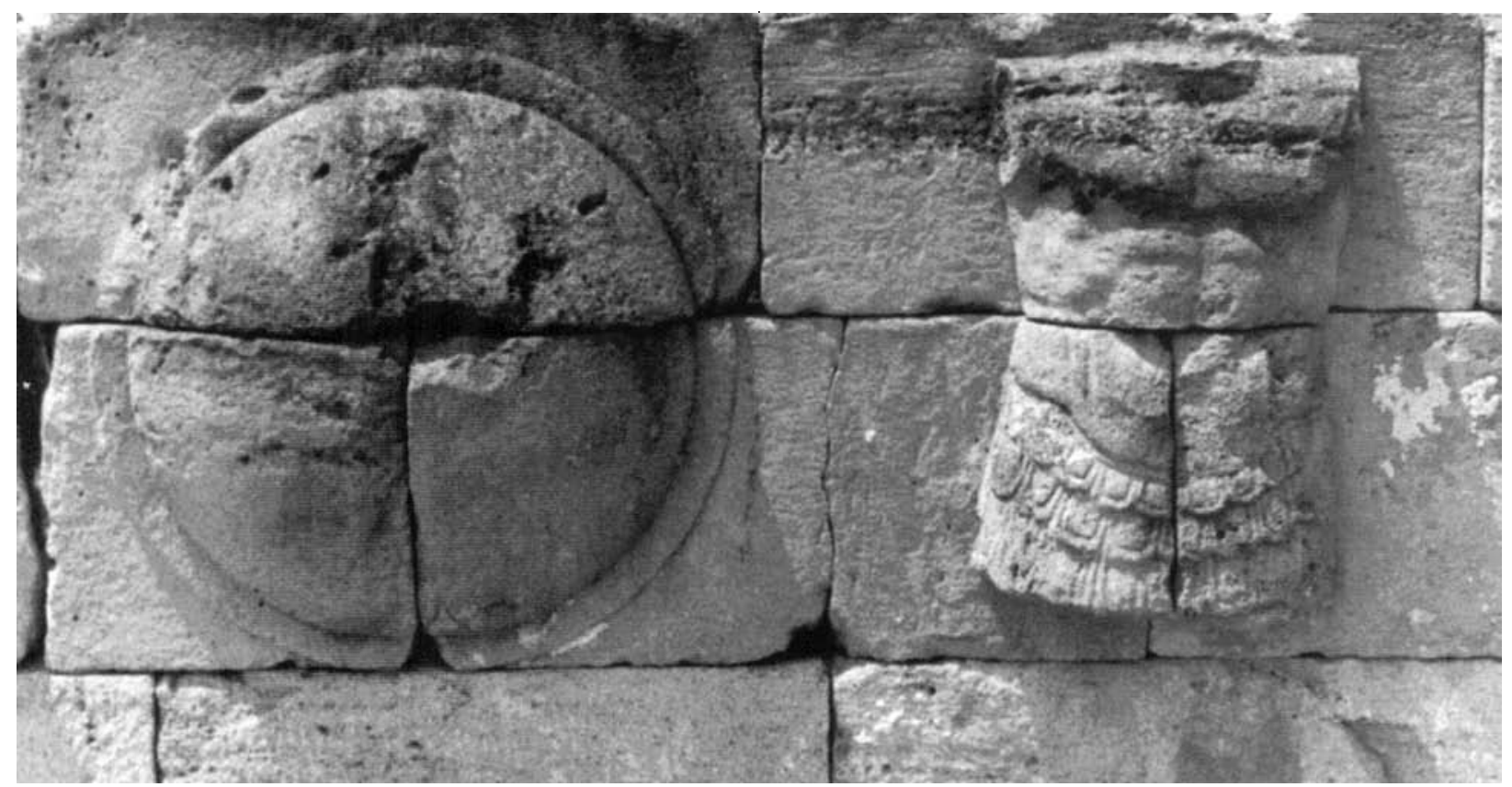

Fig. 5. Detalle del Monumento de los Escudos de Dión (Macedonia). Fuente: Polito, 1998.

Las armas en tanto que instrumentos de combate, están ligadas también a la celebración de la victoria, sobre todo las armas capturadas en el campo de batalla, ya que se identifican con el enemigo y simbolizan su derrota.

Por lo tanto, los despojos enemigos tomaban parte de los desfiles triunfales y de otras celebraciones; el tropaion originario se vestía con armamento enemigo, muchos monumentos que celebraban éxitos militares se adornaban con relieves de armas amontonadas que representaban las capturadas al enemigo, como las de los frisos de recinto porticado del santuario de Atenea Polias de Pérgamo, en los que aparecen despojos de los gálatas mezclados con armas griegas, conmemorando de este modo no sólo una victoria, sino las glorias militares, en general, de los atálidas sobre otros soberanos helenísticos y sobre los celtas (fig. 4). Esta representación de las armas amontonadas del vencido o spolia se convertirá, junto con la imagen del trofeo, en una de los motivos iconográficos más frecuentes del arte triunfal helenístico y romano ${ }^{39}$.

De todos modos, las armas esculpidas en los monumentos, ya fueran tumbas o monumentos conmemorativos no siempre tenían que ser representaciones del armamento enemigo o trofeos. Seguramente, en el caso de algunas tumbas y monumentos de victoria helenísticos decorados, sobre todo, con la alternancia de corazas y escudos, habría que hablar más que de las armas del enemigo o trofeos, de las armas propias o de motivos simbólicos, quizá de carácter apotropaico. Como puede ser el caso del monumento de Dión, que alterna escudos hoplitas con corazas de tipo anatómico y coselete (Fig. 5). Se trata de armas macedónicas que pueden fecharse entre finales del siglo IV y principios del III. Posiblemente, y como ha señalado Eugenio Polito $(1998,83)$ no representan las armas enemigas, sino las propias macedonias, que insertadas en un monumento público simbolizarían la dignidad y el poder militar macedonio.
39 Sobre los frisos de armas en la Antigüedad clásica véase el excelente trabajo de Eugenio Polito (1998): Fulgentibus Armis. Introduzione allo studio dei fregi d’armi antichi. Roma.

En el mundo romano los frisos decorados con spolia constituyen uno de los motivos más frecuentes en la ornamentación de cierto tipo de monumentos honoríficos como los arcos de triunfo, las columnas, los mausoleos, etc. Aparece, por ejemplo, en el arco de Orange (Amy et alii, 1962), en la base de la Columna Trajana, en la decoración escultórica del Foro de Trajano (Ungaro y Messa, 1989), en las pilastras del Armilustrum del Aventino de la galería de los Uffizi, en el teatro romano de Mérida (Salcedo, 1983), etc.

Para más ejemplos vide Polito, 1998. 


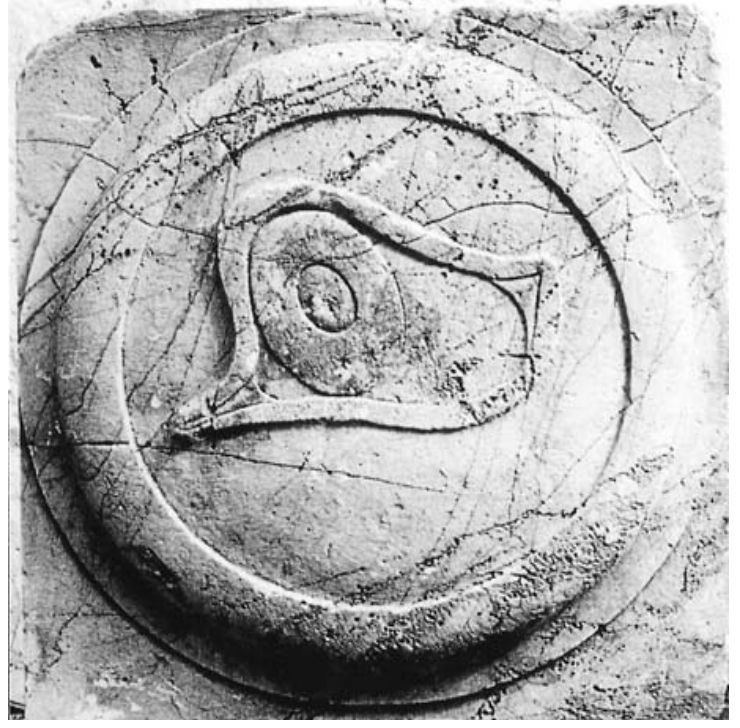

Fig. 6. Escudo decorado con un gran ojo apotropaico del monumento de Djebel Chimtou (Túnez). Fuente: Polito, 1998.

Lo mismo puede decirse de algunas de las armas que decoran el monumento númida de Chimtou, "Simitthu" (Túnez), construido por Micipsa a mediados del siglo II a. C., convertido después en un templo del dios Saturno. Como otros monumentos helenísticos el edificio está decorado con alternancia de corazas y escudos (fig. 6) que no representan armas enemigas ni trofeos, sino armamento decorado con elementos simbólicos vinculados quizá con alguna divinidad $^{40}$.

Pero volviendo a la relación del armamento con los ritos de victoria. En el mundo griego la dedicación del armamento y su exhibición en los santuarios era una manifestación de piedad, pero también un símbolo de la victoria con efecto propagandístico.

La mayoría de las piezas del equipo militar procedentes de los lugares de culto fueron dedicadas a lo largo de los períodos arcaico y clásico,

40 García-Bellido, 1998. Sobre el significado de las armas esculpidas del monumento de Chemtou vid. Polito, 1998, 86-89.

41 Sobre esta cuestión véase Gabaldón, 1997; Gabaldón, 2003.

42 Para la presencia de armas en el santuario de Poseidón en Istmia vid. Jackson, 1992.

43 Teoría apuntada por A. Jackson (1992), seguida por P. Krentz $(2002,35)$. Para este último el hecho de que se produjera este cambio y disminuyesen las ofrendas de armas en los santuarios era una regla más del agón hoplita, que según este autor fue inventado en el siglo especialmente entre comienzos del siglo VI a. C. y la primera mitad del $\mathrm{V}^{41}$.

las armas consagradas en los santuarios en este período eran sobre todo armas capturadas en el campo de batalla. Las piezas del equipo militar personal podían ser dedicadas ocasionalmente a las divinidades, aunque no fue un hecho habitual hasta fechas posteriores.

Esta práctica de dedicar el armamento del enemigo comenzó a declinar en el siglo $\mathrm{V}$ a. C. Así, por ejemplo, en el santuario de Posidón en Istmia tras el incendio que destruyó el templo arcaico en una fecha aproximada al 460 a. C. ya no volvieron a dedicarse más armas, al menos, no en la mismas cantidades ${ }^{42}$.

Algo similar ocurrió en Olimpia y Delfos, donde la cantidad de armas, datadas en el siglo $\mathrm{V}$, especialmente en su segunda mitad, es bastante menor que la de los dos siglos precedentes. De hecho, muy pocas armas procedentes del santuario de Olimpia pueden ser fechadas más allá del 430 a. C., y en Delfos, tras la ofrenda de los despojos enviados por Tegea y Mantinea en el 423 a. C. apenas hay armas procedentes del campo de batalla.

La disminución de armas en los santuarios no parece deberse a razones económicas, ya que precisamente en el siglo $\mathrm{V}$ a. C. tanto el crecimiento de la población como el económico estaban en alza más que en retroceso (Snodgrass, 1989-1990, 289).

Es posible que esta disminución de armas del botín en los lugares de culto pudiera estar, en parte, relacionada con el surgimiento de un sentimiento panhelénico que hacía que resultase poco digno llevar a los grandes santuarios las armas de griegos capturadas en el campo de batalla por otros griegos. Esto pudo contribuir a que el número de armas ofrecido en los santuarios disminuyera ${ }^{43}$, lo cual nos recuerda el lamento de Plutarco ${ }^{44}$, sacerdote en Delfos, y de

V a. C. y no en el VII a. C.

44 Esos monumentos en los que el dios está rodeado por todas partes de primicias y diezmos, que son producto de matanzas, de guerras y de saqueos, y ese templo lleno de despojos y botines tomados a los griegos, ¿podemos ver todo eso sin indignarnos?. ¿Cómo podemos no apiadarnos de los helenos cuando leemos en bellas ofrendas inscripciones tan vergonzosas como éstas: "Brasidas y los acantos con los despojos de los atenienses, "Los atenienses con los despojos de los corintios", "Los focenses con los despojos de los tesalios". (Plutarco, Sobre los oráculos de la Pitia, cap. 15). 
Platón ${ }^{45}$ al ver en los santuarios las armas de los griegos tomadas por otros griegos.

Lo cierto es que, en general, a partir del siglo $\mathrm{V}$ a. C. la presencia de armas y de otros objetos va siendo menor tras la "generosidad" del período arcaico, y no sólo en los santuarios panhelénicos sino también en los centros de culto locales.

Por otra parte, a partir de los siglos IV y III aparecen en algunos santuarios regulaciones y leyes sagradas que van a prohibir la entrada de armas procedentes del botín. De igual modo, existen datos que indican que muchos santuarios griegos no permitían que se llevaran objetos de hierro -incluyendo las armas- al interior de su recinto $^{46}$.

Lo que ocurre es que a partir del siglo $\mathrm{V}$ a. C., y sobre todo de la centuria siguiente, se dedican más auténticos monumentos que las propias armas. Se ofrecen ahora más edificios y esculturas, que son también ofrendas guerreras puesto que fueron costeadas con parte de las ganancias del botín.

De algún modo se pretende una perpetuidad, algo que esta relacionado con los cambios que el mundo griego estaba experimentado que afectaban al sistema breve y ritualizado del agón hoplita..

Por supuesto, estas transformaciones no significan en absoluto que la guerra se separase sus aspectos rituales y que no se ofreciesen más armas en los santuarios ni se levantasen más auténticos trofeos construidos con los despojos de los enemigos. El equipo militar siguió consagrándose a los dioses, aunque en cantidades menores, tanto despojos como especialmente ofrendas de las armas propias, como se puede comprobar en varios de los poemas helenísticos de la Antología Palatina (vid. Tabla I).

En efecto, las armas siguen llevándose a los santuarios como ofrendas durante el período Helenístico. Tras las batallas, se seguía honrando a los dioses, ya fuese con la ofrenda de armas o,

$45 \mathrm{Ni}$ tampoco llevaremos a los templos las armas de los caídos, como si fuesen ofrendas, y mucho menos las de los griegos, por poco que nos importe el mostrarnos benévolos con el resto de Grecia. Más bien debemos temer el contaminar los templos al llevar allí los despojos de familiares nuestros, a no ser que el dios disponga lo contrario. (Platón, República $\mathrm{V}, 470 \mathrm{a})$.

46 F. Sokolowski, Lois Sacrées des Cités Grecques, $\mathrm{n}^{\circ}$ 68, 124; F. Sokolowski, Lois Sacrées des Cités Grecques, suppl. n $33,59,60 ;$ Vid. también Plutarco, Moralia 274B-C y sobre todo, con monumentos costeados con parte del botín, y se exhibía en los recintos sagrados todo aquello que simbolizase el triunfo y la victoria. De esta manera, Alejandro Magno, tras la batalla del Gránico no sólo ordenó que se levantaran estatuas a los caídos, también envió a Atenas trescientas escudos (o panoplias), algunos de los cuales fueron colgados para su exhibición en el Partenón ${ }^{47}$.

En el primer cuarto del siglo III a. C. Pirro ofreció en el santuario de Atenea Itonia, entre Feres y Larisa, los escudos de los gálatas y los de los macedonios en Dodona tras derrotar al ejército de Antígono Gonatas ${ }^{48}$.

Tras expulsar a los gálatas de Delfos en el año 280 a. C. los etolios dedicaron escudos de oro en el santuario, los cuales podían verse todavía en tiempos de Pausanias ${ }^{49}$ colgados en la parte trasera e izquierda del arquitrabe del templo de Apolo.

De igual modo, hacia el 211 a. C., Filipo V ofreció en el santuario de Atenea en Lindo diez escudos, diez espadas y diez cascos procedentes de los despojos de sus enemigos (Pritchett, 1979, 245).

Las armas enemigas se colgaban para su exhibición no sólo en las columnas muros de los templos, también en las estoas de los centros políticos. Por ejemplo, en Pérgamo, además de los grupos escultóricos ya mencionados se exhibían, como símbolo de la victoria, los despojos de los gálatas en los nichos de dos grandes pórticos de la acrópolis de aquella ciudad. Por otro lado, según Polibio (V, 8, 8-9), cuando Filipo V marchó sobre Termo en el año 218 pudo ver quince mil piezas de armamento ornando las estoas de la ciudad etolia. Estas armas estarían en buen estado puesto que los soldados de Filipo cambiaron sus armas por las que estaban en los pórticos y destruyeron el resto.

Hasta ahora se han mencionado algunos ejemplos de la dedicación de armas enemigas en el período Helenístico ${ }^{50}$, pero las fuentes literarias señalan también las ofrendas de las armas perso-

819E; Plutarco, Arato XXI.

47 Vid. Plutarco, Alejandro XVI,17; Arriano, Anabásis I, 16,7 .

48 Leónidas, Antología Palatina VI, 130. Pausanias (I, 13, 2-3) menciona también estas ofrendas que el rey del Épiro dedica a Atenea y a Zeus tras derrotar al macedonio Antígono (274-273 a. C.).

49 Pausanias X, 19, 4.

50 Más referencias en Launey, 1987, 906-911. 


\begin{tabular}{|c|c|c|c|c|c|c|c|}
\hline & $\underbrace{0}_{y} \tilde{y}$ & $\begin{array}{l}\bar{\sigma} \\
\bar{\sigma} \\
\bar{N}\end{array}$ & $\stackrel{0}{-1}$ & $\ddot{0} \overrightarrow{.7}$ & 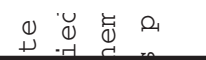 & の $0 . \bar{G}$ & $\overline{0} \gg$ \\
\hline 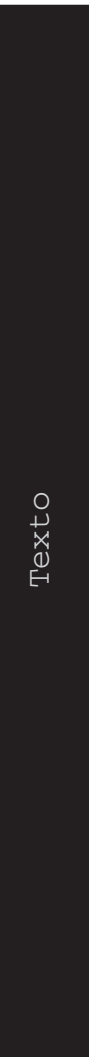 & 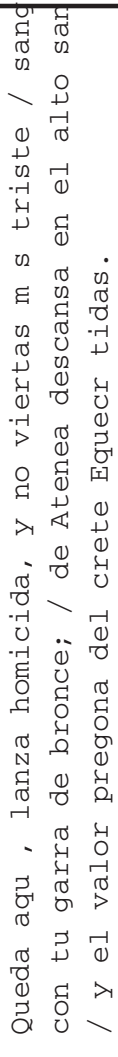 & 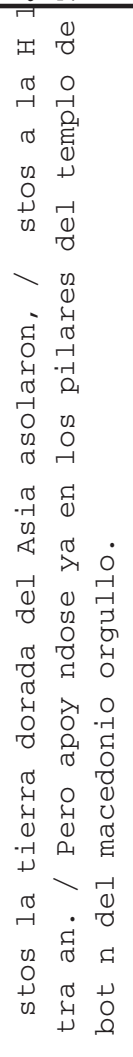 & 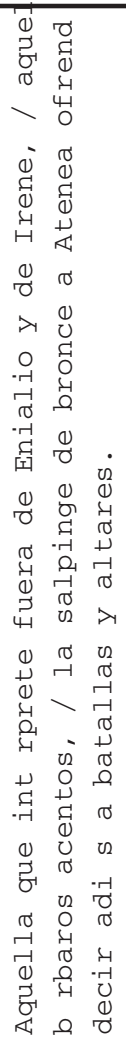 & 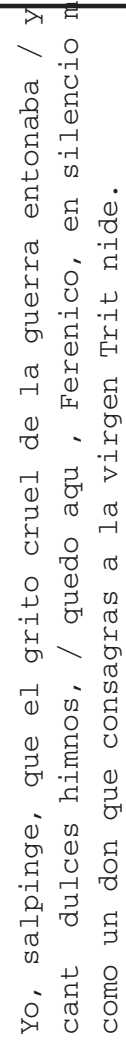 & 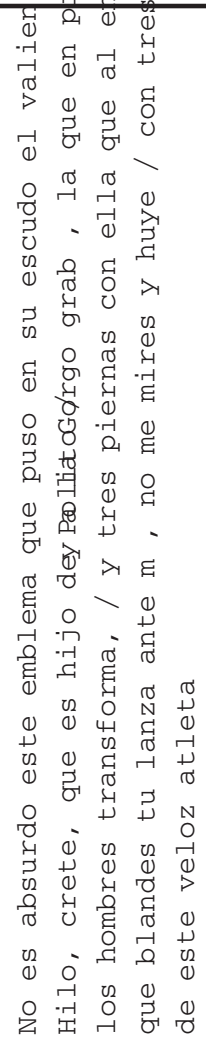 & 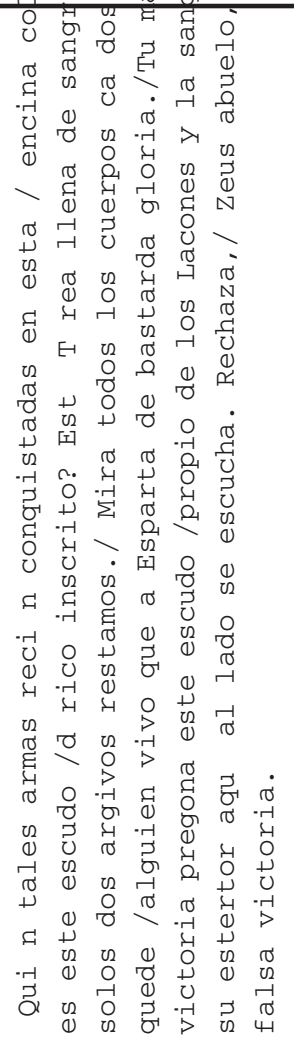 & 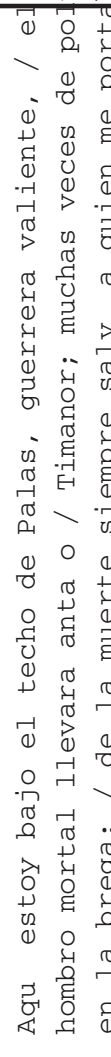 \\
\hline 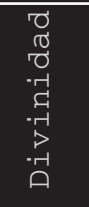 & 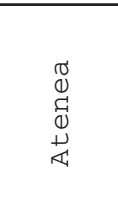 & \begin{tabular}{l} 
Un \\
\multirow{2}{N}{} \\
$N$
\end{tabular} & 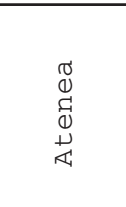 & 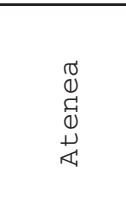 & & \begin{tabular}{l} 
Un \\
\multirow{2}{N}{} \\
$N$
\end{tabular} & 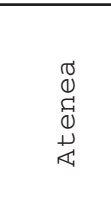 \\
\hline 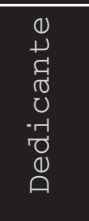 & 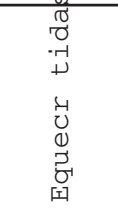 & 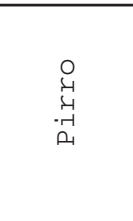 & $\begin{array}{l}0 \\
0 \\
.7 \\
0 \\
0 \\
y \\
0 \\
\text { w }\end{array}$ & 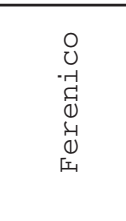 & $\begin{array}{l}0 \\
\text { - } \\
\text { 㝞 }\end{array}$ & & 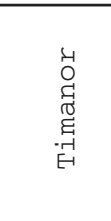 \\
\hline 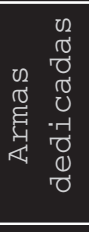 & 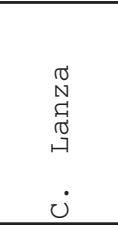 & $\begin{array}{l}\text { 0n } \\
00 \\
0 \\
0 \\
\text { un } \\
\text { ma }\end{array}$ & 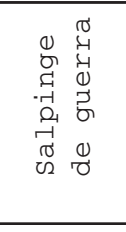 & 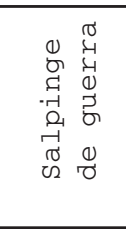 & $\begin{array}{l}0 \\
0 \\
] \\
0 \\
\text { un } \\
\text { In }\end{array}$ & 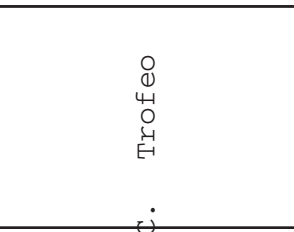 & $\begin{array}{l}\text { o } \\
\text { J } \\
0 \\
0 \\
\text { un } \\
\text { in }\end{array}$ \\
\hline $\begin{array}{l}0 \\
\mathcal{1} \\
0 \\
0 \\
{[1}\end{array}$ & $\begin{array}{l}\dot{\sigma} \\
\stackrel{H}{H} \\
\dot{H} \\
\dot{v}\end{array}$ & & & & $\begin{array}{l}\dot{0} \\
\circ \\
\stackrel{N}{N} \\
\dot{G}\end{array}$ & $\begin{array}{l}\dot{\sigma} \\
\stackrel{\infty}{m} \\
\sim \\
\dot{G}\end{array}$ & $\begin{array}{l}\dot{\sigma} \\
\circ \\
\dot{m} \\
\dot{\mu}\end{array}$ \\
\hline 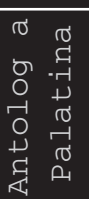 & 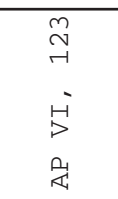 & 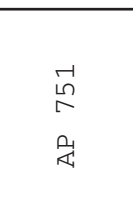 & 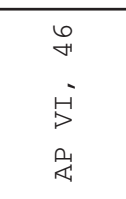 & 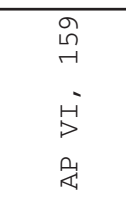 & 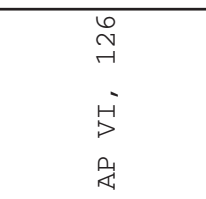 & $\begin{array}{l}0 \\
\text { m } \\
\forall \\
\dot{H} \\
\dot{H} \\
5 \\
0\end{array}$ & 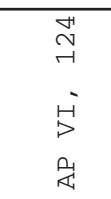 \\
\hline 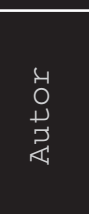 & 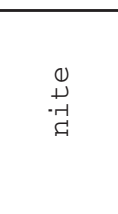 & 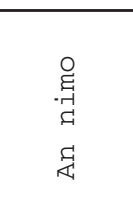 & 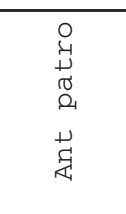 & 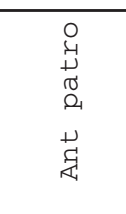 & $\begin{array}{l}0 \\
0 \\
0 \\
.-1 \\
y \\
0 \\
0 \\
0 \\
.01 \\
0\end{array}$ & $\begin{array}{l}0.0 \\
0 \\
.0 \\
-1 \\
0 \\
0 \\
02 \\
.0 \\
-1 \\
0\end{array}$ & $\begin{array}{l}0 \\
0 \\
.1 \\
-1 \\
02 \\
0 \\
0 \\
0 \\
0 \\
4\end{array}$ \\
\hline
\end{tabular}




\begin{tabular}{|c|c|c|c|c|c|c|c|}
\hline ع & G & ن & $\underbrace{10}_{0} \pi$ & मै & 舟 & 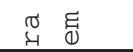 & - ت્પ \\
\hline 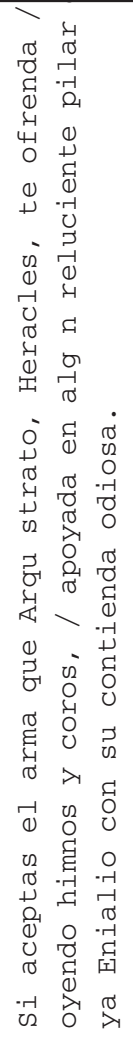 & 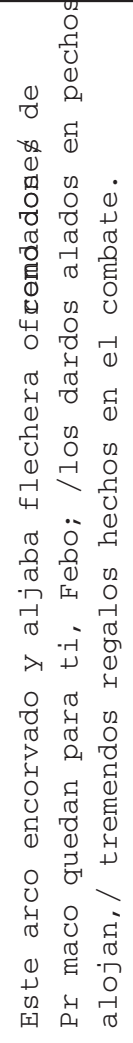 & 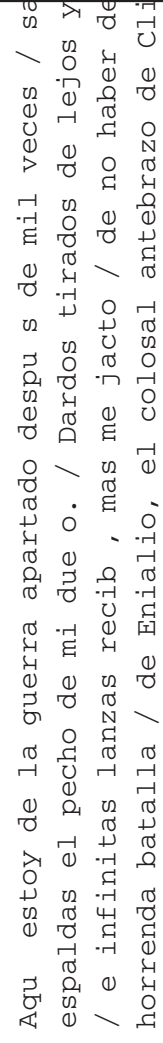 & 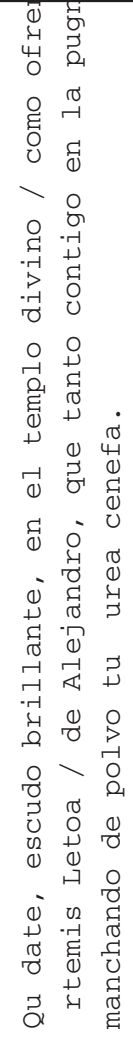 & 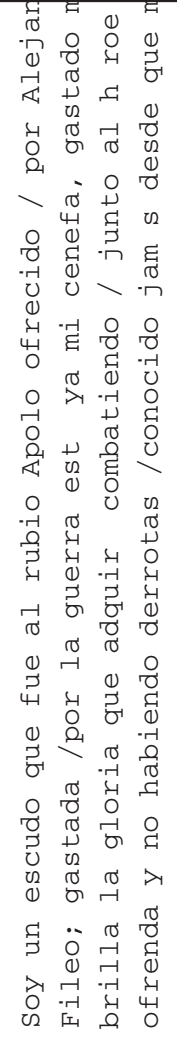 & 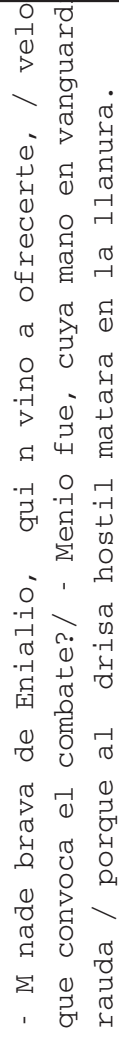 & 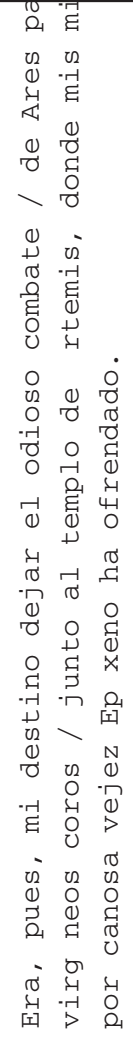 & 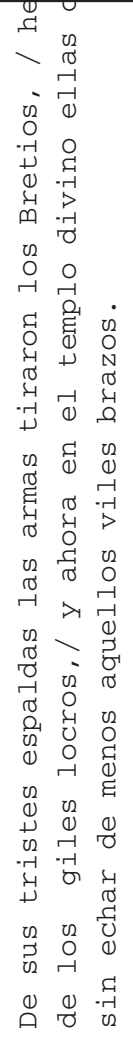 \\
\hline \multirow[t]{2}{*}{$\begin{array}{l}\text { v } \\
0 \\
0 \\
0 \\
0 \\
0 \\
0 \\
0 \\
w\end{array}$} & $\begin{array}{l}0 \\
\text { Oे } \\
\text { Oे } \\
\text { 家 }\end{array}$ & & 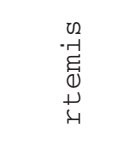 & 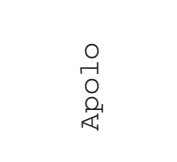 & 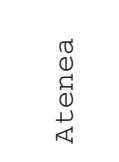 & 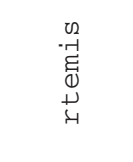 & \\
\hline & 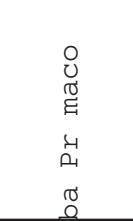 & $\begin{array}{l}0 \\
. \\
.-1 \\
\vec{u}\end{array}$ & $\begin{array}{l}0 \\
0 \\
0 \\
0 \\
0 \\
0 \\
-0 \\
0 \\
-1\end{array}$ & 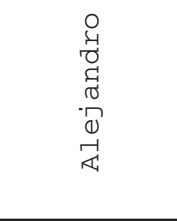 & $\begin{array}{l}\circ \\
-\overrightarrow{0} \\
\stackrel{0}{\Xi}\end{array}$ & 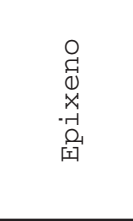 & \\
\hline $\begin{array}{l}0 \\
\text { O } \\
3 \\
0 \\
\text { un } \\
\text { In }\end{array}$ & 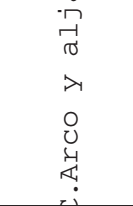 & 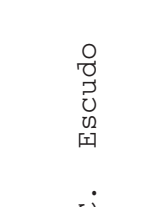 & $\begin{array}{l}0 \\
\text { ] } \\
3 \\
0 \\
\text { Un } \\
\text { |r }\end{array}$ & & $\begin{array}{l}\sigma \\
N \\
\mathbb{E} \\
\widetilde{\sigma} \\
\mapsto\end{array}$ & $\begin{array}{l}0 \\
0 \\
3 \\
0 \\
\text { un } \\
\text { ma }\end{array}$ & $\begin{array}{l}\text { n } \\
\text { o } \\
3 \\
0 \\
\text { un } \\
\text { na }\end{array}$ \\
\hline $\begin{array}{l}\dot{\sigma} \\
\circ \\
\stackrel{一}{m} \\
\dot{\epsilon}\end{array}$ & $\begin{array}{l}\dot{\sigma} \\
\stackrel{\circ}{\stackrel{n}{N}} \\
\stackrel{\dot{q}}{ }\end{array}$ & $\begin{array}{l}\dot{\sigma} \\
\circ \\
\stackrel{\leftrightarrow}{N} \\
\dot{\dot{C}}\end{array}$ & $\begin{array}{l}\dot{\sigma} \\
\stackrel{\leftrightarrow}{\sim} \\
\stackrel{n}{N}\end{array}$ & $\begin{array}{l}\dot{\sigma} \\
\stackrel{\circ}{\circ} \\
\stackrel{n}{N} \\
\dot{\dot{H}}\end{array}$ & & & $\begin{array}{l}\dot{\sigma} \\
\circ \\
\dot{m} \\
\dot{0}\end{array}$ \\
\hline 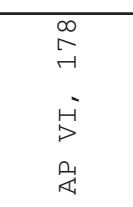 & $\begin{array}{l}\dot{9} \\
\dot{H} \\
P \\
\stackrel{4}{4}\end{array}$ & 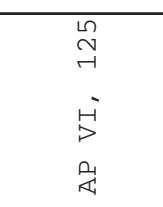 & 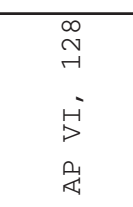 & 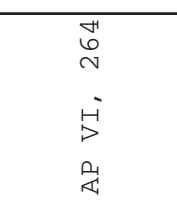 & 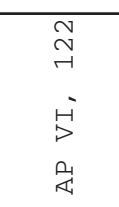 & 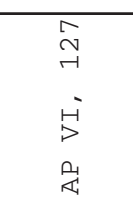 & $\begin{array}{l}\underset{\sim}{N} \\
\overrightarrow{+} \\
\dot{P} \\
\dot{P} \\
\dot{\alpha}\end{array}$ \\
\hline 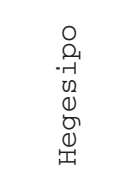 & $\begin{array}{l}02 \\
0 \\
0 \\
0 \\
0 \\
0 \\
0 \\
0 \\
\sum \\
\sum\end{array}$ & $\begin{array}{l}02 \\
0 \\
0 \\
0 \\
0 \\
0 \\
0 \\
0 \\
0 \\
\vdots \\
\Sigma\end{array}$ & $\begin{array}{l}0 \\
0 \\
0 \\
0 \\
0 \\
0 \\
0 \\
0 \\
0 \\
\vdots \\
1\end{array}$ & $\begin{array}{l}0 \\
0 \\
0 \\
0 \\
0 \\
0 \\
0 \\
0 \\
0 \\
0 \\
1\end{array}$ & $\begin{array}{l}n \\
-0 \\
-1 \\
0 \\
-1 \\
z\end{array}$ & $\begin{array}{l}n \\
-0 \\
-1 \\
0 \\
-1 \\
-1\end{array}$ & $\begin{array}{l}0 \\
0 \\
.0 \\
-12 \\
c_{2}\end{array}$ \\
\hline
\end{tabular}




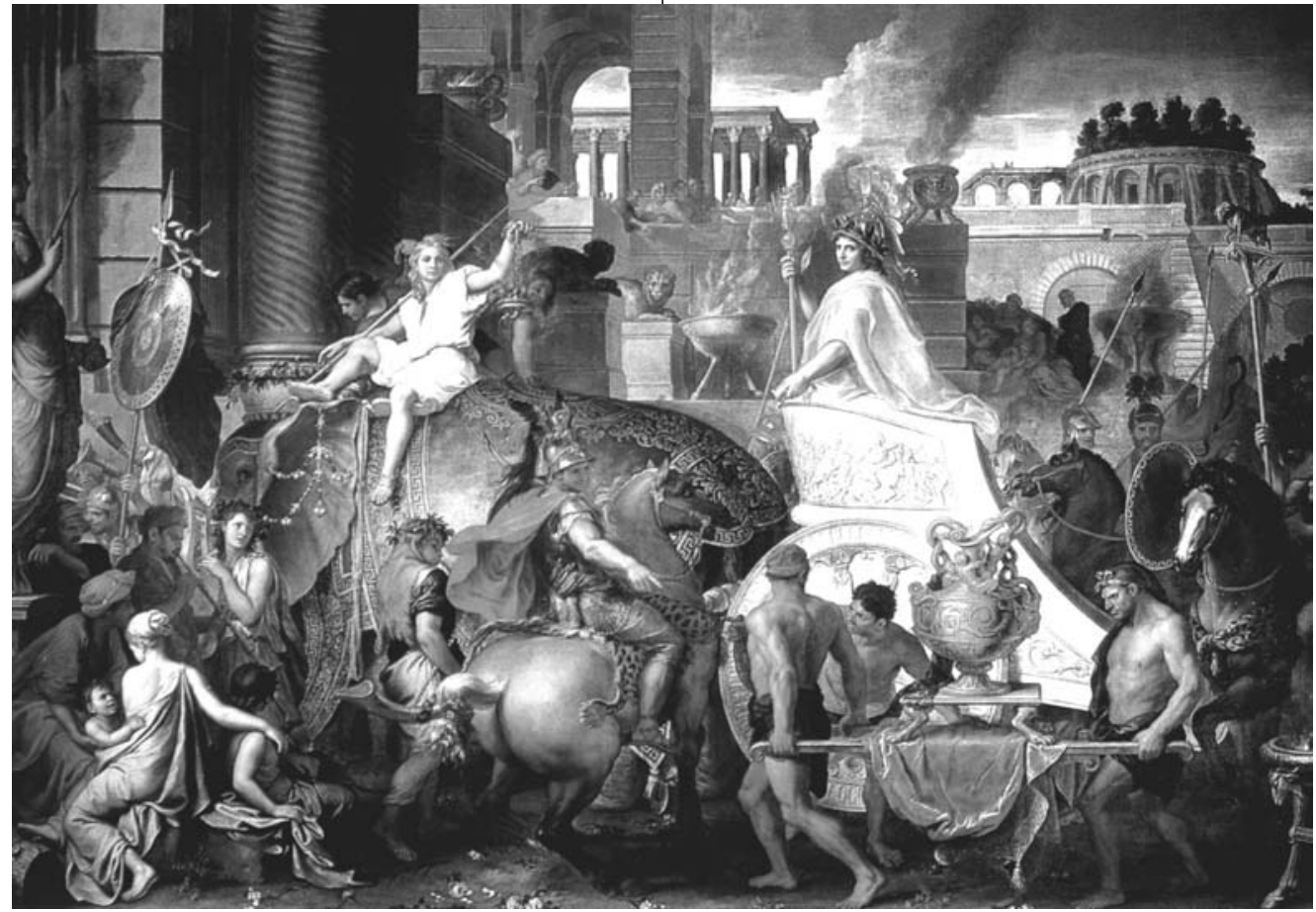

Fig. 7. Gran lienzo que el pintor del barroco francés Charles Le Brun (1619-1690) pintó para Luis XIV. Representa la entrada triunfal de Alejandro en una fastuosa Babilonia, reflejando la gloria militar y las virtudes del monarca macedonio. Museo del Louvre.

nales en los santuarios.

La Antología Palatina (vid. Tabla I) recoge una serie de poemas en los que el armamento personal es dedicado tras cumplir su vigencia.

De este modo, en un epigrama de Mnasalces es un escudo el que habla:

Soy un escudo que fue al rubio Apolo ofrecido /por Alejandro, el hijo de Fileo;/ gastada por la guerra está ya mi cenefa, gastado mi vientre,/pero brilla la gloria que adquirí combatiendo /junto al héroe campeón que me ofrenda y no habiendo derrotas /conocido jamás desde que me forjaron ${ }^{51}$.

La consagración de las armas propias con la indicación del nombre del dedicante era sin duda un gesto propagandístico.

De Alejandro se decía que había ofrecido su coraza y su lanza en el santuario de Asclepio en Gortina de $\operatorname{Arcadia}^{52}$, y que, en su viaje a Ilio, consagró a Atenea su armadura y tomó prestadas de su santuario armas que databan de los tiem-

\footnotetext{
51 Trad. M. Fernández-Galiano.

52 Pausanias, VIII, 28, 1 .

53 Arriano, Anábasis I, 11,7-8

54 Pausanias, III, 3, 8.

55 Pausanias, VI, 19, 6 .

56 Por ejemplo, Livio, X, 7, 9: (...) Domus spoliis hostium adfixis insignes inter alias.
}

pos de la Guerra de Troya ${ }^{53}$. Aquí, Alejandro es presentado como un personaje singular, el cual no sólo tiene la potestad para utilizar las armas míticas de los que combatieron en Troya, sino que además, al igual que aquellos héroes, consagra sus armas en los lugares de culto, las cuales quedarán allí para ser admiradas por las generaciones sucesivas como si se tratase de reliquias, al igual que las armas de los héroes, como la lanza de Aquiles que según Pausanias se guardaba en el santuario de Atenea en Faselis ${ }^{54}$ o la espada de Pélope custodiada en el tesoro de los sicionios en Olimpia ${ }^{55}$.

De igual manera, como señalan las fuentes escritas, en la Roma republicana los generales romanos también solían llevar parte de los despojos al interior de la ciudad, con los que ornaban no sólo los templos, sino también otros lugares públicos y sus propias casas (Wiseman, $1987)^{56}$.

Vide también Polibio VI, 39, 10 y Livio, XXIII, 23, 6. Seguramente, la propia casa de Augusto tenía armas en la puerta de entrada. Vid. Ovidio Tristes III, 1, 33 ss: Singula dum miror video fulgentibus armis / conpiscuos postes tectaque digna deo.

Colocar las armas en la domus era un privilegio (Livio, X, $7,9)$. 
Del mismo modo otros pueblos itálicos, como los samnitas, como analiza el profesor Gianluca Tagliamonte en este mismo volumen, llevaban, como lo hacían los griegos, las armas propias y las capturadas al enemigo a sus lugares de culto más destacados, como el santuario de Pietrabbondante (Isernia).

También, en el ámbito ibérico, se han hallado algunas armas ofensivas de hierro en el santuario del Cerro de los Santos (Albacete), que, pese a su pésima conservación, pueden ser interpretadas como ofrendas a la divinidad o divinidades del lugar en relación con algún acontecimiento mili$\operatorname{tar}^{57}$.

Finalmente, además de la construcción de los monumentos conmemorativos y de la dedicación de armas a los dioses, otro de los mecanismos que convertían la victoria en imagen del poder, consistía en la celebración de rituales públicos, que incluían los sacrificios a los dioses, que empezaban en el mismo campo de batalla (antes y después del inicio de las hostilidades), y las procesiones triunfales.

Los ritos que tenían lugar tras el enfrentamiento bélico estaban dotados de un especial sentido religioso y propagandístico. Sin duda, las ceremonias públicas que celebraban victorias militares, muchas de ellas con gran impacto escénico, dieron a los reyes helenísticos nuevas oportunidades de aparecer ante un público más amplio y consolidar su poder. El efecto, aunque transitorio, entre la población era importante ya que esta o parte de ella podía participar directamente en muchos de estos festejos. Además, la ritualidad y teatralidad de muchos de estos desfiles triunfales lograrían que la celebración de la victoria, permaneciera en la retina del público y convirtiera a los jefes victoriosos en una especie de dioses (fig. 7).

Los grandes desfiles de los reyes helenísticos, relacionados con otras ceremonias religiosas, como la espectacular procesión en Alejandría de Ptolomeo II Filadelfo (c. 271/270 a. C.), descrita por Ateneo ${ }^{58}$, o la enorme procesión al santuario de Apolo en Dafne organizada por Antíoco IV Epifanes entre el 166 y 165 a. C., que fue costea-

57 En último lugar, Sánchez, 2002, 247-249.

58 Sobre la procesión de Ptolomeo Filadelfo véase un estudio muy completo en Rice, 1983.

59 Vid. Polibio, XXX, 25-26.

60 Otro ejemplo es el de la entrada de Demetrio I en Atenas con ocasión de los misterios eleusinos. Allí fue recibido por coros que cantaban en su honor y fue considerado casi como un dios. Vid. Rice, 1983. da con parte del botín de su guerra contra Egipto $^{59}$, eran indudables muestras de propaganda militar ${ }^{60}$.

Lo mismo ocurría con la celebración del Triunfo romano ${ }^{61}$ o con la ceremonia y desfile de los Spolia Opima, que culminaba con la consagración de los mejores despojos en el templo de Júpiter Feretrio ${ }^{62}$.

Algo similar puede verse también en las escenas del retorno del guerrero, frecuentes en las lastras pintas de las tumbas de Paestum del siglo IV a. C., en las que el guerrero itálico regresa con los spolia del enemigo ensartados en su lanza como si fueran trofeos, seguido de varios prisioneros de guerra ${ }^{63}$.

En todos estos casos estos desfiles y rituales se celebraban fundamentalmente el hecho de la victoria y se manifestaba el poder del dirigente o jefe victorioso.

Sin embargo, como ha señalado acertadamente el profesor Hölscher $(2003$, 14), en época arcaica y clásica, los rituales se centraban sobre todo en la figura del guerrero, más que en su propia victoria. El foco de atención no se ponían tanto en la gloria de la victoria como en el valor del guerrero. De hecho en las imágenes de los vasos pintados el tema más recurrente es la partida del joven guerrero a la batalla o armándose para la misma y no el regreso victorioso ${ }^{64}$. Además, en las épocas arcaica y clásica apenas había monumentos conmemorativos personalizados, el trofeo originario era una dedicación anónima a la divinidad y no una exaltación duradera de la victoria. Sin embargo, los soberanos helenísticos querían y necesitaban que sus victorias tuvieran una imagen duradera como un mecanismo más para consolidar su poder político, en el marco de una "realeza triunfal" que legitimaba su poder.

\section{Bibliografía}

AmAndry, P. (1978): “Consécration d'armes galates à Delphes”, Bulletin de correspondance hellénique 102, 571-581.

61 Vid. Versnel, 1970; McCormick, 1986; Pietilä-Castrén, 1987.

62 Para el tema de los spolia opima véase por ejemplo el trabajo de H. Flower (2000).

63 Para las lastras pintadas de las tumbas de Paestum vid. Pontrandolfo y Rouveret, 1992.

64 Como aparece en las lastras pintadas de Paestum. 
Amy, R. et alii (1962): L'arc d Orange. Gallia, Suppl. 15. París.

Betalli, M. (e. p.): "I trofei sui campi di battalglia nel mondo greco". MEFRA (Mélanges de lÉcole Française de Rome- Antiquité), 113 (2).

Broneer, O. (1941): The Lion Monument at Amphipolis. Cambridge, Mass.

Calcani, G. (1989): Cavalieri di bronzo. La torma di Alessandro opera di Lissipo. Studia Archaeologica 53. Roma.

CAMP, J. et alii (1992): "A Trophy from the Battle of Chaironeia of 86 B.C." American Journal of Archaeology 96, 443-455.

Castellví, G. et alii (1995): "La identificación de los trofeos de Pompeyo en el Pirineo". Journal of Roman Archaeology 8, 5-18.

Cohen, A. (1997): The Alexander Mosaic. Stories of victory and defeat. Cambridge.

Conti, G. (2001): "Da albero-trofeo a trofeo-croce", Rendiconti della Pontificia Accademia Romana di Archeologia 71 (serie III), 273-326.

FEDAK, J. (1990): Monumental tombs of the Hellenistic Age: A study of selected tombs from the Pre-Classical to the Early Imperial Era. Phoenix, suppl. 27. Toronto.

Fernández nieto, F. J. (1975): Los acuerdos bélicos en la Antigua Grecia. T. 1. Texto. Santiago de Compostela.

Flower, H. (2000): "The tradition of the Spolia Opima: M. Claudius Marcellus and Augustus", Classical Antiquity 19 (1), 34-64.

Gansiniec, Z. (1955): Geneza Tropaionu. Biblioteka Archeologiczna 5. Varsovia / Wroclaw.

Gabaldón Martínez, M. M. (1997): "El trofeo griego. Ritual de armas y símbolo de la victoria”, Boletín de la Asociación Española de Amigos de la Arqueología 37, 29-40.

Gabaldón Martínez, M. M. (1999): Rituales de armas: una aproximación arqueológica e histórica a su estudio en los santuarios griegos. Memoria de Licenciatura inédita. Universidad Autónoma de Madrid.

Gabaldón Martínez, M. M. (2003): Ritos de armas en la Edad del Hierro. Lugares de culto y armamento en el ámbito circunmediterráneo. Tesis doctoral inédita. Universidad Autónoma de Madrid.

GARCíA-Bellido, M. P. (1998): "Sobre la identificación de Dea Caelestis en monumentos del Museo del Bardo (Túnez)". J. L. Cunchillos et alii (Ed.): El Mediterráneo en la Antigüedad: Oriente y Occidente. Actas del Congreso. Sapanu. Publicaciones en Internet II (1998). [www.labherm.filol.CSIC.es]
HÖLSCHER, T. (2003): "Images of war in Greece and Rome: between military practicee, public memory, and cultural symbolism ", Journal of Roman Studies, 92, 1-17

Hope, V. M. (2003): "Trophies and tombstones: commemorating the Roman soldier". World Archaeology 35(1), 79-97.

JaCQUemin, A. (1999): "Guerre et offrandes dans les sanctuaires", Guerres et Sociétés,1999, Pallas 51, 141157.

JACQUEMIN, A. (2000): Guerre et religion dans le monde grec (490-322 av.J.-C.). Lieja.

JACKSON, A. (1992): "Arms and armour in the Panhellenic sanctuary of Poseidon at Isthmia". W. Coulson y H. Kyrieleis (Eds.):Proceedings of an international Symposium of the Olimpic Games. Atenas, 141-144

Janssen, A. J. (1957): Het antieke Tropaion. Ledeberg / Gent.

Krentz, P. (2002): "Fighting by the rules. The invention of the hoplite agôn”, Hesperia 71, 23-39.

Launey, M. (1987): Recherches sur les Armées Hellénistiques II. Reimpresión con addenda y puesta al día por Y. Garlan, P. Gauthier y C. Orrieux. París.

LONIS, R. (1979): Guerre et Religion en Grèce á lÉpoque Classique. París.

MARKLe, M. M. (1994): "A shield monument from Veria", Mediterranean Archaeology 7, 83-97.

MARKLe, M. M. (1999): "A shield monument from Veria and the chronology of Macedonian shield types", Hesperia 68 (2), 219- 254.

MACKAY, C. S. (2000): "Sulla and the monuments: studies in his public persona.", Historia 49 (2), 161-210.

McCormick, M. (1986): Eternal Victory. Triumphal rulership in Late Antiquity, Byzantium and the early Medieval West. Cambridge.

MeiggS, R. y Lewis, D. (EDS.) (1988): A selection of Greek historical inscriptions to the end of the fifth century $B . C$. Oxford.

Moreno, P. (1994): Scultura ellenistica.2 vols. Madrid.

Olaguer-Feliú de y Alonso, F. (2000): Alejandro Magno y el arte. Madrid.

PICARD, G. C. (1957): Les trophées romains. Contribution à thistoire de la Religion et de lArt triomphal de Rome.París.

Pietilä-Castren, L. (1987): Magnificentia publica. The victory monuments of the roman generals in the era of the Punic Wars. Commentationes Humanarum Litterarum, 
84. Helsinki.

Polito. E. (1996): "I portici e le armi. Un motivo iconografico e il suo spazio architettonico e ideale", Rendiconti della Accademia dei Lincei 9, 7, 593-600.

POLITO, E. (1998): Fulgentibus Armis. Introduzione allo studio dei fregi d’armi antichi. Xenia Antiqua Monografie. Roma.

Pollitt, J. J. (1998): El arte helenístico. Madrid.

Pontrandolfo, A.; Rouveret, A. (1992): Le tombe dipinte di Paestum. Módena.

PrÉaux, C. (1984): El Mundo Helenístico. Grecia y Oriente (323-146 a. C.). Barcelona.

Pritchett, W. K. (1971-1985): The Greek State at War. IIV. Berkeley / Los Angeles / Londres.

Reinach, A. J. (1913a): "Trophées macédoniens", Révue des Etudes Grecques 26, 347-398.

Rice, E. (1983): The Grand Procession of Ptolemy Philadelphus. Oxford.

RICE, E. (1993): “The glorious dead: Conmemoration of the fallen and portrayal of victory in the late Classical and Hellenistic World". J. Rich y G. Shipley (Eds.): War and Society in the Greek World. Londres / N. York. 224-256.

Roger, J. (1939): "Le monument au lion d'Amphipolis", Bulletin de correspondance hellénique 63, 4-42.

Sánchez Gómez, M. L. (2002): El santuario de el Cerro de los Santos (Montealegre del Castillo, Abacete). Nuevas aportaciones arqueológicas. Albacete.
SNODGRASS, A. M. (1989-1990): "The economics of dedication at greek sanctuaries". Anathema. Regime delle offerte e vita dei santuari nel mediterraneo antico (Atti del Convegno Internazionale 15-18 giugno 1989). Scienze dell Antichitá. Storia. Archeologia, Antropologia 3-4, 287-294.

TAGLiAmonte, G. (1989-1990): "Iscrizioni votive italiche su armi". Anathema. Regime delle offerte e vita dei santuari nel mediterraneo antico (Atti del Convegno Internazionale 15-18 giugno 1989). Scienze dell Antichitá. Storia. Archeologia, Antropologia 3-4, 519-534.

Ungaro, L.; Messa, L. (1989): "Pannelli con rilievi d'armi dal Foro di Traiano: nota preliminar", Archeologia Classica 41, 215-236.

VANDERPOOL, E. (1966): "A monument to the Battle of Marathon”, Hesperia 35, 93-106.

Versnel, H. S. (1970): Triumphus. An inquiry into the origin, development and meaning of the Roman triumph. Leiden.

Wallace, P.W. (1969): "Psyttaleia and the Trophies of the Battle of Salamis", American Journal of Archaeology 73, 293-302.

West III, W.C. (1969): "The trophies of the Persian Wars", Classical Philology 64, 7-19.

Wiseman, T. P. (1987): "Conspicui postes tectaque digna deo: the public image of aristocratic and imperial houses in the late Republic and Early Empire", $L^{\prime}$ Urbs. Espace Urbain et Histoire (Ier siècle av. J.-C.-IIIe siècle ap.J. C.). Roma, 393-413. 